\title{
Avila Beach: From Funky to Fabulous
}

\author{
Amanda Ross \\ Master of City and Regional Planning student, Cal Poly
}

Among California's coastal communities, Avila Beach may be the one most defined by its history. Amanda Ross discusses the unique planning and redevelopment process there, starting with the cleanup of a decades-long crude oil spill that had contaminated the soil and led to the reconstruction of its beach and the entire historic downtown. This article reflects part of the activies for Professor Paul Wack's Plan Implementation graduate class in 2015.

A vila Beach grew as a funky small fishing town from its founding in in the late 19th Century as the main shipping port for San Luis Obispo. Buildings sprung up as the population grew, defining a downtown along the beachfront (Figure 1). In 1906, Union Oil Co. built a 95-acre oil tank farm on higher ground next to the city and by World War II, 2 million gallons of crude oil a day were being pumped into tankers (Figure 2). Despite these operations, Avila Beach remained a quaint small town with a popular beach.

The appeal, built environment, and character of the town were forever changed in the early 1990s with the discovery that 22,000 gallons of crude oil from Unocal operations had been contaminating the soil under and surrounding the downtown for decades. The oil tanks leaked and so did the pipes that went under Front Street to connect to the tankers. Unocal agreed to pay $\$ 200$ million in cleanup costs and damages in what was considered to be the largest environmental settlement in California's history at the time. About 300,000 cubic yards of soil - sometimes 15 feet deep- had to be removed and replaced. The entire downtown including several residences were razed to remove the contaminated soil.

\section{Path to Rebuilding}

Town rebuilding began with a series of community workshops leading to the Avila Beach Specific Plan, adopted by the San Luis Obispo Board of Supervisors in October 2000 and approved by the California Coastal Commission in November 2001. Out of the 395 residents of Avila Beach at the time, 200 were involved in the process. The plan's major goal was to provide Avila Beach with a design character that replicated the pre-existing informality and human-scaled features, besides strengthening the interface with the beach. James Caruso, one of San Luis Obispo County's senior planners responsible for the Specific Plan, presented an overview of the process

The Avila Beach Specificy Plan was developed by San Luis Obispo County's Planning Department under the direction of Victor Hollanda, with the assistance of Design, Community \& Environment, Earth Design Inc., Bay Area Economics, and RRM Design Group (San Luis Obispo). It can be downloaded from <http://www.slocounty.ca.gov/planning/ General_Plan_Ordinances_and_Elements/Specific_Plans.htm highlighting both successful and not so successful features, and accompanied students on a study visit.

\section{Front Street}

Starting at a new community park on its north end and running along the beachfront, Front Street is a fundamental element of the Specific Plan. A comfortable sidewalk next to the sand turns into a block-long comfortable pedestrian promenade where traffic lanes were blocked and vehicular access is allowed only for emergency and occasional loading and unloading.

Front Street's pedestrian block coincides with the pier and was planned as a hub for Avila Beach, allowing for an animated and flexible public space for café seating, outdoor vendors, observation decks, access points to the beach, and special events (Figure 3a). The local weekly Farmer's Market is held there providing locally grown foods, fresh fish and seafood, live music, wine tasting, art, and various vendors. Tourist-oriented businesses, restaurants and bars along this segment provide extensive outdoor seating and help animate the promenade. There are plenty opportunities to enjoy Avila Beach's wonderful climate and views to the ocean.

The design for Front Street incorporates attractive and innovative streetscaping features, all ADA compliant. Planters

Figure 1: The Avila Grocery store in 1925, an example of the old town's architectural character. The building was removed for the clean-up and rebuilt on Front Street. (source: Avila Beach Specific Plan)

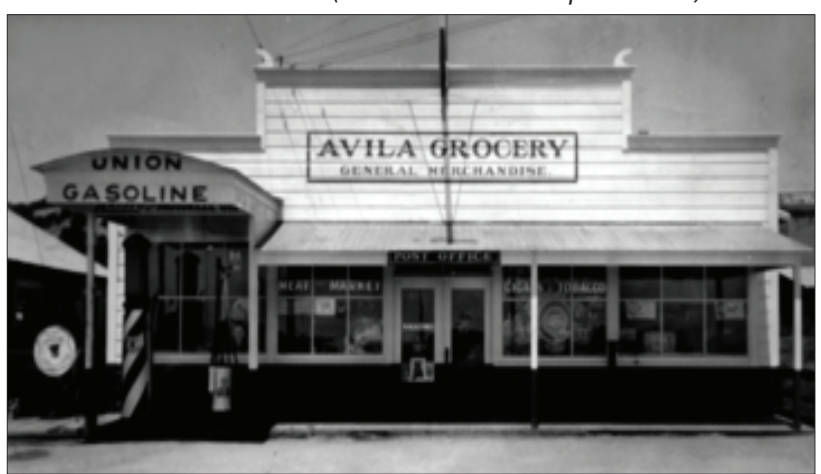


rented out their apartments and live elsewhere. In one instance, the original residents who lived above their shop decided to move out due to the noise from the bar next door, what indicates that the mixed-use ideal has unplanned consequences.

Overall, the facade articulation and the second story additions to the Front Street redevelopment were artfully added, and in combination of the lively atmosphere generated by the visitorserving uses, eateries and bars, contribute successfully to a lively small town feel (Figure 3b).

\section{Design Elements}

Besides the carefully crafted standards for architecture, streetscaping, and signage, two important design elements add to the success of the Avila Beach Specific Plan:

\section{Artwork}

As part of the redesign, local artists were summoned to collaborate. One of the most popular pieces is a beautiful floor inlay located at the Front Street promenade by local artists Tres Feldman and Ginny Vreeland. It depicts the history of Avila Beach, highlighting major historic moments and elements including the original Chumash settlement, the building of the pier, the fishing, the Avila Lighthouse, the building of the oil tanks, the oil spill, and the new redevelopment (Figure 6).

To deter skateboarders from riding on railings, benches and pavements areas, beautiful metal sea creatures such as seastars and shells, were placed on their corners (Figure 7). Created for the first time for Avila Brach, this idea has since become quite popular and has been used in many projects.

\section{Community Park}

Before the redevelopment plan, apart from the open space provided by the beach, there was no park space to serve local families and children. During the plan-making community workshops, a park was one of the most important demands.

Originally a mobile-home park, the site chosen for the community park anchors the Front Street promenade on the north and connects directly to the beach (Figure 8). The park includes a playground, a basketball court, picnic tables, barbecue pits, drinking fountains, bike racks, and public restrooms with outside showers for beach goers. Following the plan's concept, the park also includes a community-oriented public building, now the Central Coast Aquarium at Avila Beach.

The park is considered a huge success by the community as it constantly in used by families, both local and visitors, nonprofits, and school children during field trips. The popular Bob Jones bike trail, which eventually will connect to the city of San Luis Obispo, ends at the Avila Beach park.

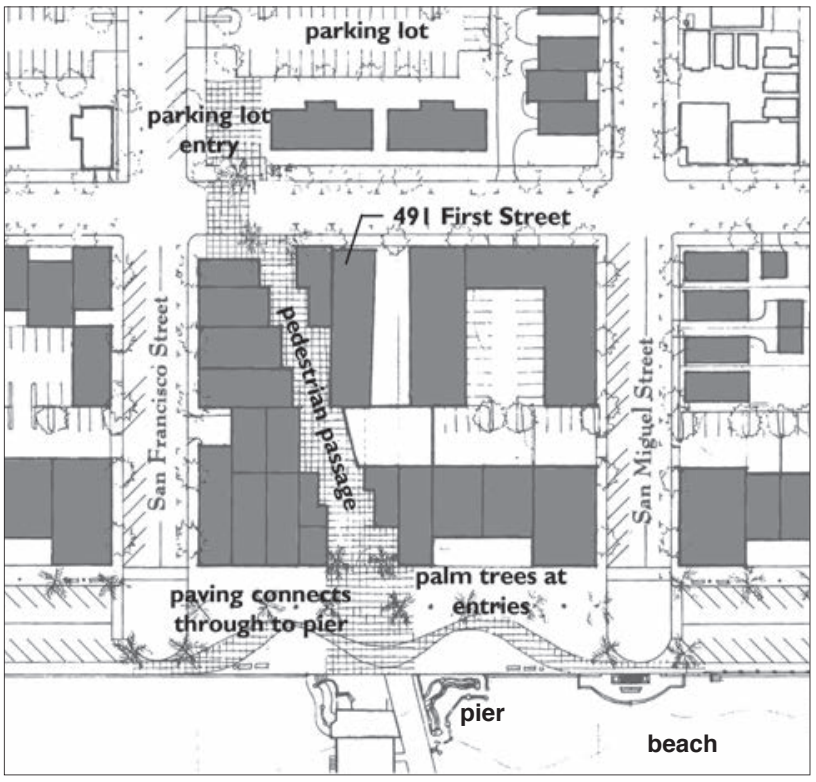

Figures $4 a \& b$ : The concept for Landing Passage suggested a more linear connection to the beach than what was built. (sources: Avila Beach Specific Plan and Google earth)

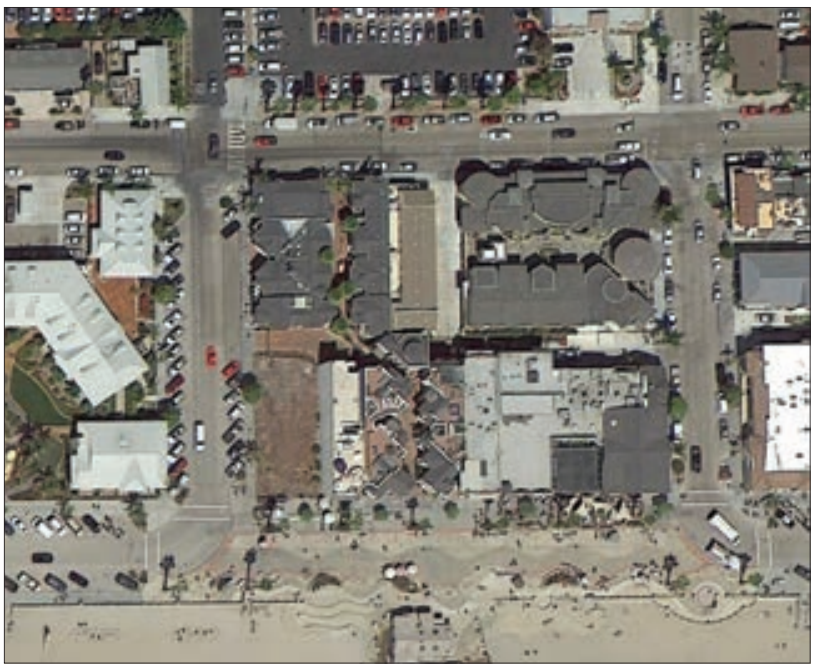

Figure 5: Example of the Front Street Commercial District Design Standards from the Avila Beach Specific Plan.

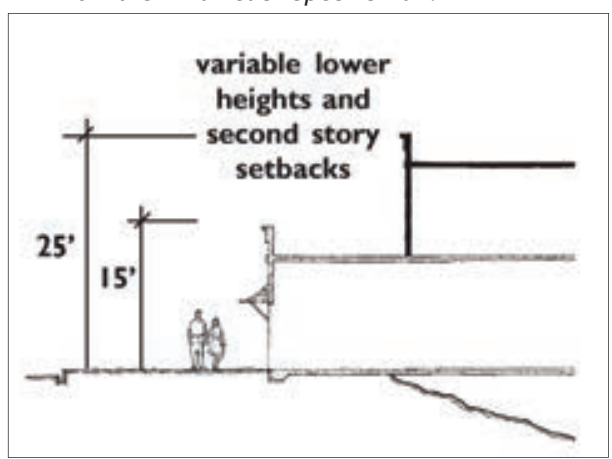




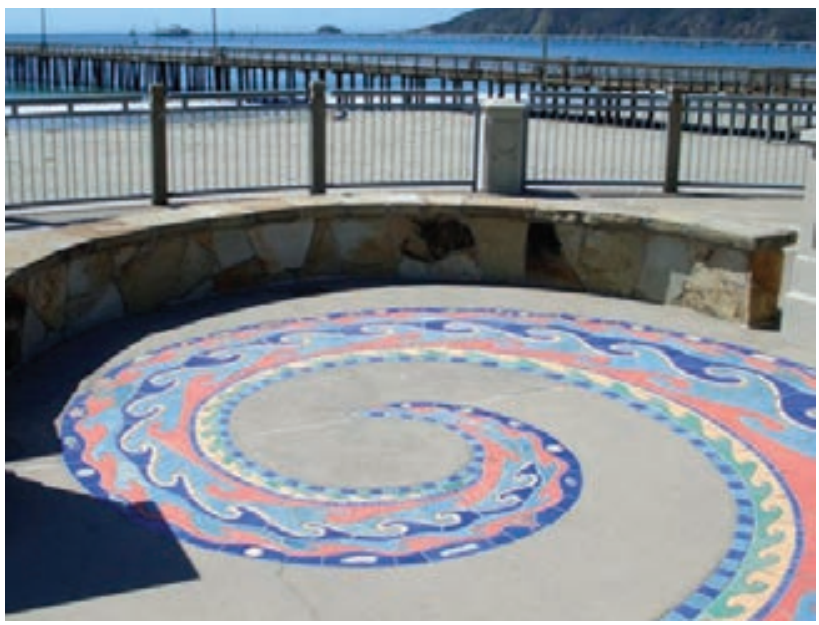

Figure 6: The Circle of Life mosaic by local artists Tres Feldman and Ginny Vreeland, located at the Front Street Promenade (see lower right corner of Figure $4 b$ ).

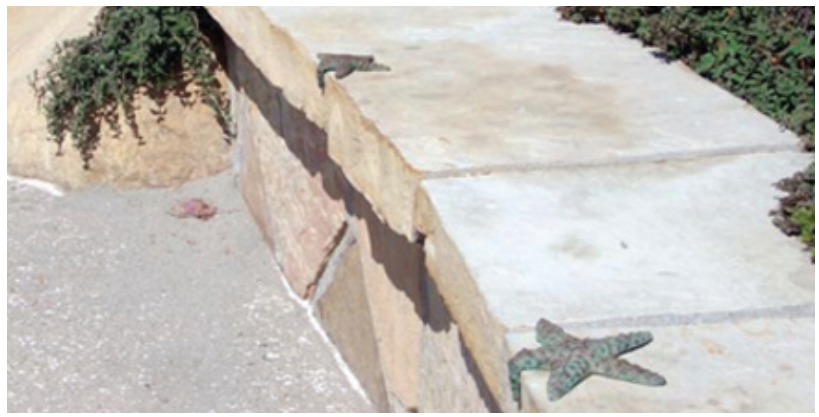

Figure 7: Bronze sea-stars prevent skaters damaging planters and benches

Figure 8: The concept for Front Street Park.

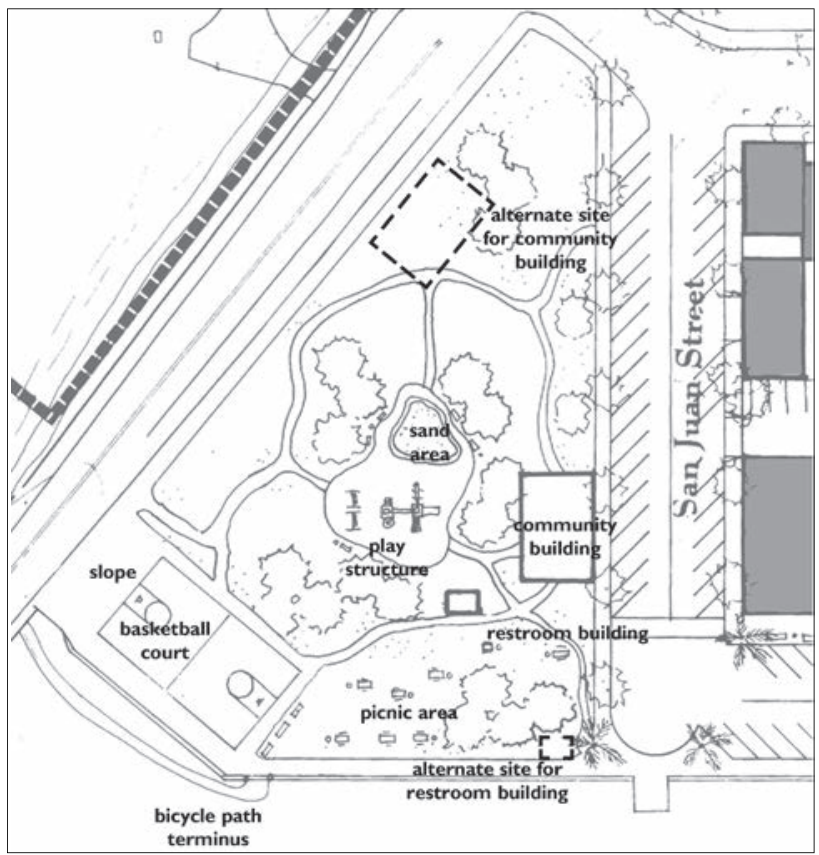

\section{Lessons Learned}

Reviewing the Avila Beach Specific Plan and comparing its intentions with the town we see today provides us with a few lessons that may be useful for other communities facing a similar situation.

The discovery of the oil spill and the subsequent tense process leading to cleanup and reconstruction held the community together. The strong support for the participatory plan process, the many inputs and ideas from the community was a testament to their love of their home. When disaster strikes, it is important for communities such as Avila to have their voices heard when it comes to redevelopment.

Today, many residents are not happy with the new development and the crowds of visitors attracted by the beach and the tourist-oriented uses. However, this can be interpreted as disappointment with the inability to recreate the past, or frustration with the need to raze the town in order to rebuid it. From another perspective, tourists and the new arrivals see Avila as a haven to enjoy the many retail and eating opportunities, and the beauty of the central coast.

Vehicular circulation has always been a major problem in Avila Beach due to the single two-lane access road and the town's limited area and geography. The success of the Specific Plan and the redevelopment caused a significant increase in the number of visitors arriving by car. Conflicts and safety issues are evident, and the lack of parking is very serious: as the existing public parking lot and street parking spaces get filled, visitors park along the shoulders of the access road for a couple of miles on popular holidays. The community's proximity to the Diablo Canyon nuclear power station and other eventual emergency situations add concern to the already over-stressed circulation system.

Although some of the plan's objectives and design elements did not result as predicted, most were implemented with great success and add to the uniqueness of Avila Beach. The most unpredicted result of the redevelopment was certainly its own success and extreme popularity, what may serve as an alert to other towns since new problems are created.

Perhaps the main moral of Avila Beach's case study is how untrustworthy oil companies are with the responsibility of monitoring their own facilities, pipes, and operations, but that is a story for another time. 